\title{
Electrochemical Fabrication of Niobium Silicon Alloys from Oxide Powder Mixtures
}

\author{
Fanke Meng and Huimin Lu \\ School of Materials Science and Engineering, Beihang University, No.37 Xueyuan Road, Haidian District, Beijing 100191, China
}

Correspondence should be addressed to Fanke Meng; fankemeng0208@gmail.com

Received 14 January 2013; Accepted 31 January 2013

Academic Editors: Y. S. Chang, P. Lukac, A. Pinkerton, and Y.-d. Wang

Copyright (C) 2013 F. Meng and H. Lu. This is an open access article distributed under the Creative Commons Attribution License, which permits unrestricted use, distribution, and reproduction in any medium, provided the original work is properly cited.

$\mathrm{NbSi}$ alloys were prepared by direct electrochemically reducing four mixed $\mathrm{Nb}_{2} \mathrm{O}_{5}$ and $\mathrm{SiO}_{2}$ powders $(\mathrm{Nb}-10 \mathrm{Si}, \mathrm{Nb}-20 \mathrm{Si}, \mathrm{Nb}-30 \mathrm{Si}$, and $\mathrm{Nb}-37.5 \mathrm{Si}$ ) in molten $\mathrm{CaCl}_{2}$ electrolyte at $900^{\circ} \mathrm{C}$. The samples were characterized with scanning electron microscope (SEM), $\mathrm{X}$-ray diffraction (XRD), and energy-dispersive X-ray spectroscopy (EDX). No oxidized phases were remained by XRD tests. Under $\mathrm{SEM}, \mathrm{Nb}$ phase was scattered in $\mathrm{Nb}_{5} \mathrm{Si}_{3}$ phase for the samples of Nb-10Si, Nb-20Si, and Nb-30Si. For the sample of Nb-37.5Si, only $\mathrm{Nb}_{5} \mathrm{Si}_{3}$ was obtained after electrolysis.

\section{Introduction}

Nickel alloys are the mostly used superalloys in aviation industry. Due to the demand of exploring new generation aircraft turbine engines, scientists and engineers are devoted to investigate less expensive superalloys with higher melting points to substitute the Ni-based alloys $[1,2]$. Following this idea, NbSi alloys (0.5-37.5 at \% Si) are attracting more and more attention because of the high melting points of the two composed phases (melting points: $\mathrm{Nb}, 2469^{\circ} \mathrm{C} ; \mathrm{Nb}_{5} \mathrm{Si}_{3}$, $2520^{\circ} \mathrm{C}$ ) in the alloy system [1]. Moreover, NbSi alloys still have three other excellent properties: close coefficient of heat expansion of the two compositions $\left(\mathrm{Nb}, 7.3 \times 10 \mathrm{k}^{-1}\right.$; $\left.\mathrm{Nb}_{5} \mathrm{Si}_{3}, 6.1 \times 10 \mathrm{k}^{-1}\right)$, relative lower density $\left(7.16 \mathrm{~g} \mathrm{~cm}^{-3}\right)$, and reasonable strength at high temperature. Thus, $\mathrm{NbSi}$ alloys are considered to be a potential candidate of the next generation superalloys. Until now, the mainly used techniques for fabricating $\mathrm{NbSi}$ alloys are orientation solidification [3], smelting with argon arc [4], physical vapor deposition (PVD), as well as some other methods of powder metallurgy. Generally, all of these techniques have the following procedures: first, extracting pure $\mathrm{Nb}$ and $\mathrm{Si}$ from minerals; second, melting and mixing molten $\mathrm{Nb}$ and $\mathrm{Si}$ by using arc or electron beam melting method; third, casting the mixed molten alloys to ingots. However, the notorious weakness of the process is resulted from high energy consumption and complex production procedures. As a typical example, the only commercial process for the production of metallic $\mathrm{Nb}$ is reducing $\mathrm{K}_{2} \mathrm{NbF}_{7}$ or $\mathrm{Nb}_{2} \mathrm{O}_{5}$ with sodium reduction or carbothermal reduction, respectively [5]. For production of silicon, the conventional technique is reducing $\mathrm{SiO}_{2}$ with carbothermal reduction technique. The typical reduction temperature is as high as $1700^{\circ} \mathrm{C}$, which therefore needs intensive energy and releases carbon oxides as wasted gases in the process [6]. Also, another critical disadvantage should be paid more attention: it is difficult to homogenize $\mathrm{Nb}$ and $\mathrm{Si}$ in any melting process due to the very high melting point of metallic $\mathrm{Nb}$.

During the recent decade, in order to produce highmelting-point metals and superalloys, many new skills were studied by scientists and engineers. Among them, direct electrochemical reduction of metal oxides or mixed oxides in molten electrolytes was an effective method for production of metals and alloys. The typical examples were FFC Cambridge Process and the derived methods. In this process, metal oxides were pressed to solid pellets as a cathode and the graphite were acted as an anode, which were soaked into the molten $\mathrm{CaCl}_{2}$ at about high temperatures $\left(700-900^{\circ} \mathrm{C}\right)$ for electrolysis simultaneously. Consequently, a potential was loaded between the two electrodes. Generally, this technique was used in production of many metals and nonmetals for 
example, $\mathrm{Cr}, \mathrm{Si}, \mathrm{Nb}, \mathrm{Ni}$, and $\mathrm{Zr}$ [7-12]. The whole reaction process can be described with the following equations:

Cathode

$$
\mathrm{AO}_{X}+2 x \mathrm{e}^{-}=\mathrm{A}+x \mathrm{O}^{2-}
$$

Anode

$$
2 \mathrm{O}^{2-}-4 \mathrm{e}^{-}+\mathrm{C}=\mathrm{CO}_{2} \text { or } \mathrm{O}^{2-}-2 \mathrm{e}^{-}+\mathrm{C}=\mathrm{CO}
$$

In these equations, the $\mathrm{A}$ is a symbol of metal or nonmetal elements. If the cathode was mixed oxides, the reduction production might be oxygen-free alloys. Therefore, this electrochemical method can be effectively used for refractory metals, high-melting-point nonmetals, and superalloys.

Herein, we used this electrochemical reduction method for the production of NbSi alloys in the molten $\mathrm{CaCl}_{2}$ at high temperature $\left(900^{\circ} \mathrm{C}\right)$. The processors were mixed $\mathrm{Nb}_{2} \mathrm{O}_{5}$ and $\mathrm{SiO}_{2}$ powders of four various atomic ratios of $\mathrm{Nb}$ and $\mathrm{Si}$. After electrolysis, the NbSi alloys were successfully obtained. After scanning electron microscope (SEM), X-ray diffraction (XRD), and energy-dispersive X-ray spectroscopy (EDX) analysis, the $\mathrm{NbSi}$ alloys were composed of different phases and almost free of oxygen. Therefore, this electrochemical reduction method had paved a way for the $\mathrm{NbSi}$ alloys production, which is also able to be applied to fabricate other refractory alloys.

\section{Experimental Details}

2.1. Materials Preparation. In this research work, the electrolyte was $\mathrm{CaCl}_{2}$. In this work, $\mathrm{CaCl}_{2}(\geq 99.0 \%), \mathrm{Nb}_{2} \mathrm{O}_{5}$ (>99.9\%), and $\mathrm{SiO}_{2}(>99.8 \%)$ powders were purchased from Chengde Optical and Electrical Materials Ltd., Hebei Province, China. The pellets preparation was following the below steps. First, $\mathrm{CaCl}_{2}$ powders were dried at $80^{\circ} \mathrm{C}$ overnight and then pressed to small cylindrical blocks with a pressure of $30 \mathrm{MPa}$. Second, the cylindrical blocks were dried again at $80^{\circ} \mathrm{C}$ for several hours and then pulverized to small $\mathrm{CaCl}_{2}$ pellets with an average sized less than $1 \mathrm{~mm}$. For the preparation of the $\mathrm{Nb}_{2} \mathrm{O}_{5} / \mathrm{SiO}_{2}$ pellets, the process was identical as that used for $\mathrm{CaCl}_{2}$ pellets preparation. The $\mathrm{Nb}_{2} \mathrm{O}_{5}$ and $\mathrm{SiO}_{2}$ powders were mixed with the atomic ratios of $\mathrm{Nb}-10 \mathrm{Si}(\mathrm{Nb}, 90$ at \%; Si, 10 at \%), Nb-20Si (Nb, 80 at $\%$; $\mathrm{Si}, 20$ at \%), $\mathrm{Nb}-30 \mathrm{Si}$ (Nb, 70 at \%; Si, 30 at \%), and $\mathrm{Nb}-37.5 \mathrm{Si}(\mathrm{Nb}, 62.5$ at \%; $\mathrm{Si}, 37.5$ at \%) between $\mathrm{Nb}$ and $\mathrm{Si}$. The total mixed powder was $200 \mathrm{~g}$. The graphite crucibles (inner diameter: $\sim 9.0 \mathrm{~cm}$, height: $\sim 18.0 \mathrm{~cm}$, wall thickness: $\sim 1.0 \mathrm{~cm}$ ) were cleaned with ethanol $(>95 \%$, Beijing Keshi Co. Ltd. Beijing, China) for at least 5 times until the inner walls of the graphite crucible were almost free of graphite powders. At last, the mixed $\mathrm{Nb}_{2} \mathrm{O}_{5} / \mathrm{SiO}_{2}$ pellets were placed in the cleaned crucible and then the $\mathrm{CaCl}_{2}$ pellets $(\sim 2000 \mathrm{~g})$ were placed on the top of the $\mathrm{Nb}_{2} \mathrm{O}_{5} / \mathrm{SiO}_{2}$ pellets.

2.2. Potentiostatic Electrolysis. The process of electrolysis was conducted in a programmable temperature-controlled furnace produced by China Iron \& Steel Research Institute Group. The design of the instrument was shown in

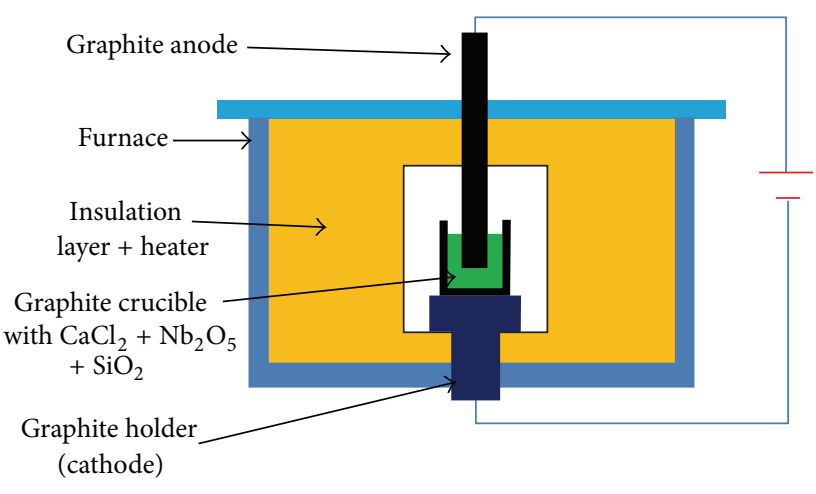

FIGURE 1: Schematic of eletrolysis system.

the schematic of Figure 1. The graphite crucible filled with $\mathrm{Nb}_{2} \mathrm{O}_{5} / \mathrm{SiO}_{2}$ and $\mathrm{CaCl}_{2}$ was placed in a graphite stage in the furnace. As an anode, a graphite rod (diameter: $6.0 \mathrm{~cm}$ ) was just hanged above the crucible vertically by a mechanic instrument, which can push the graphite rod move up and down to ensure that the rod can contact with the molten electrolyte during the whole electrolysis process. The direct current for the electrolysis was supplied by a KGHF-1000A/6V rectifier, made by Beijing Chunshu Electric rectifier Ltd., Beijing, China. The temperature-controlled furnace was vacuumed and then filled with argon $(\geq 99.9 \%$, $\mathrm{O}_{2} \leq 10 \mathrm{ppm}, \mathrm{H}_{2} \mathrm{O} \leq 15 \mathrm{ppm}, \mathrm{N}_{2} \leq 5 \mathrm{ppm}$ ) as soon as possible. It should be noted that the argon flow was maintained with a rate of $1.0-1.5 \mathrm{~L} \mathrm{~min}^{-1}$ and the outlet was adjusted with a valve to ensure that the gas pressure inside the furnace was about $0.01 \mathrm{MPa}$ larger than the ambient pressure, which was helpful for avoiding air to ingress into the furnace in the electrolysis process. The heating process was of three steps: first, the temperature was heated to $780^{\circ} \mathrm{C}$ with a ramping rate of $10^{\circ} \mathrm{C} \mathrm{min}{ }^{-1}$; second, kept at $780^{\circ} \mathrm{C}$ for $30 \mathrm{~min}$, the $\mathrm{CaCl}_{2}$ electrolyte was completely melted in the crucible; third, the temperature continued to rise up to $900^{\circ} \mathrm{C}$ with a heating rate of $10^{\circ} \mathrm{C} \mathrm{min}^{-1}$. Consequently, the potential was loaded and then stabilized at $3.0 \mathrm{~V}$ for electrolysis between the two electrodes. The electrolysis would be lasted for about 45 hours, and the graphite crucible with the products was removed out the furnace as the temperature in the furnace was decreased to room temperature after electrolysis. The product was obtained by smashing the crucible.

2.3. Characterizations of Morphology and Composition. Micrograph and composition analyses were conducted with a VEGA\\LMU SEM system equipped with a CCD camera, from TESCAN. EDX equipment was purchased from OXFORD and analysis software was INCA. The phase composition of the NbSi alloys was identified by a Rigaku D/Max 2200 PC X-ray diffractometer.

\section{Results and Discussion}

After electrolysis at $900^{\circ} \mathrm{C}$ in molten $\mathrm{CaCl}_{2}$, the samples were obtained. Figure 2 showed the pictures of the obtained 


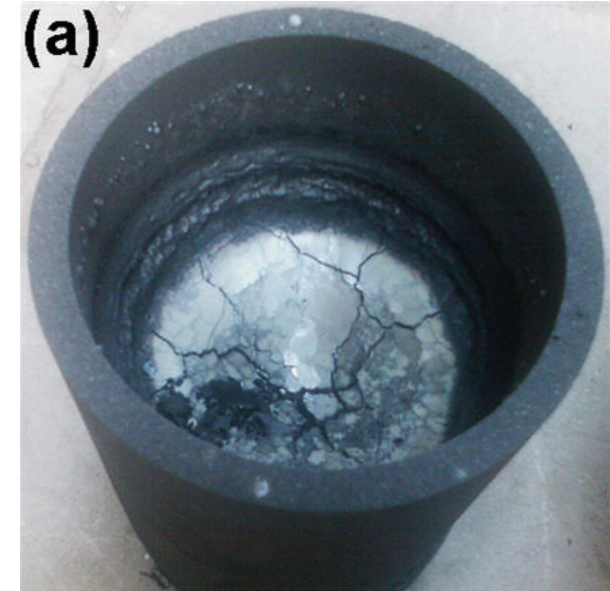

(a)

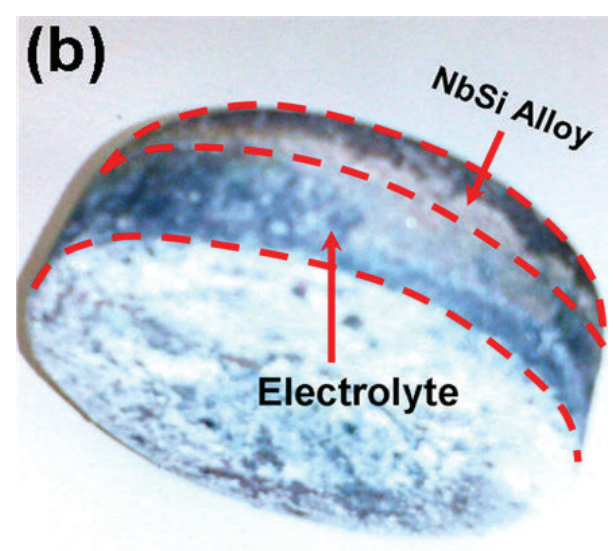

(b)

Figure 2: (a) top view of the crucible after electrolysis; (b) the sample with electrolyte after electrolysis.

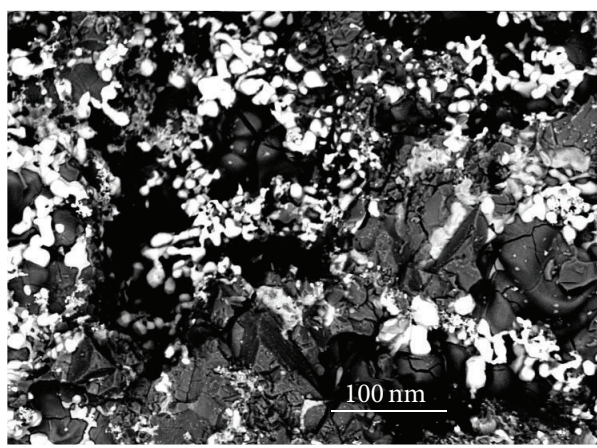

(a)

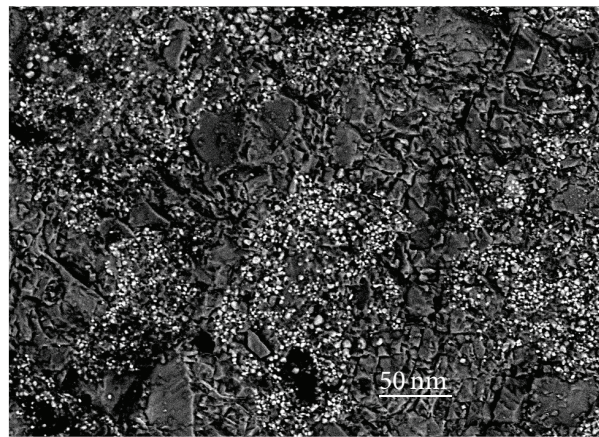

(c)

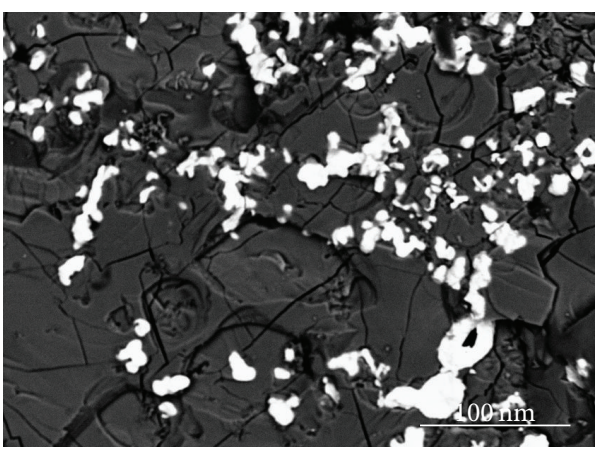

(b)

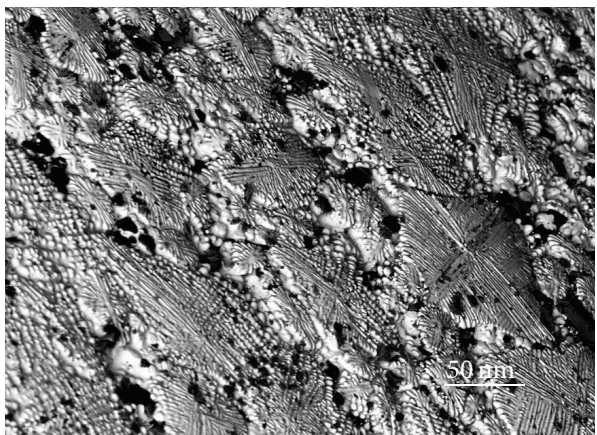

(d)

Figure 3: SEM images of four samples with different Nb/Si ratio: (a) Nb-10Si; (b) Nb-20Si; (c) Nb-30Si; (d) Nb-37.5Si.

product after electrolysis. As shown in Figure 2(a), the $\mathrm{CaCl}_{2}$ electrolyte and the sample were molten together after electrolysis. By smashing the crucible, a block of ingot was obtained in Figure 2(b). Clearly, the ingot had two layers of different materials. A metal-like layer with a color of grayish was rich of alloys and other layer was mainly composed of electrolyte.

It should be noted that Figure 2 only showed typical pictures after electrolysis of the processor powder for the alloy of $\mathrm{Nb}-37.5 \mathrm{Si}$. The other three samples were also of a similar picture, which were not shown here. The morphologies of the alloys were shown in the SEM images in Figure 3. The white small particles with an average size about 10-20 nm had $\mathrm{Nb}$ concentration of 98.2 at \% in Table 1. On the contrary, the concentrations of the $\mathrm{Si}$ and the $\mathrm{O}$ were only 1.6 at \% and 0.2 at $\%$, respectively. Therefore, it was clearly to show that the white small particles were mainly composed of $\mathrm{Nb}$. In the grey areas, the concentrations of NB and Si were 89.4 and 10.1 at \% respectively, which was almost equated to the ratio of $\mathrm{Nb}-10 \mathrm{Si}$ 


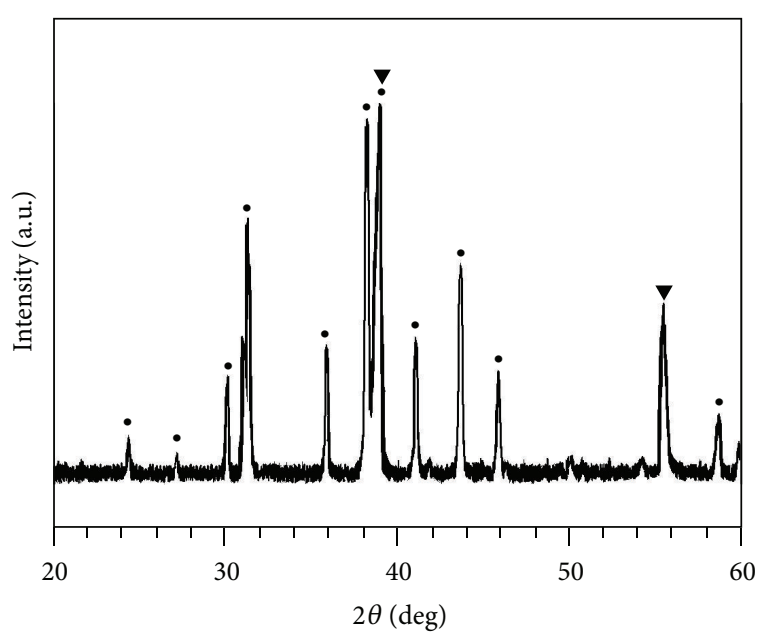

(a)

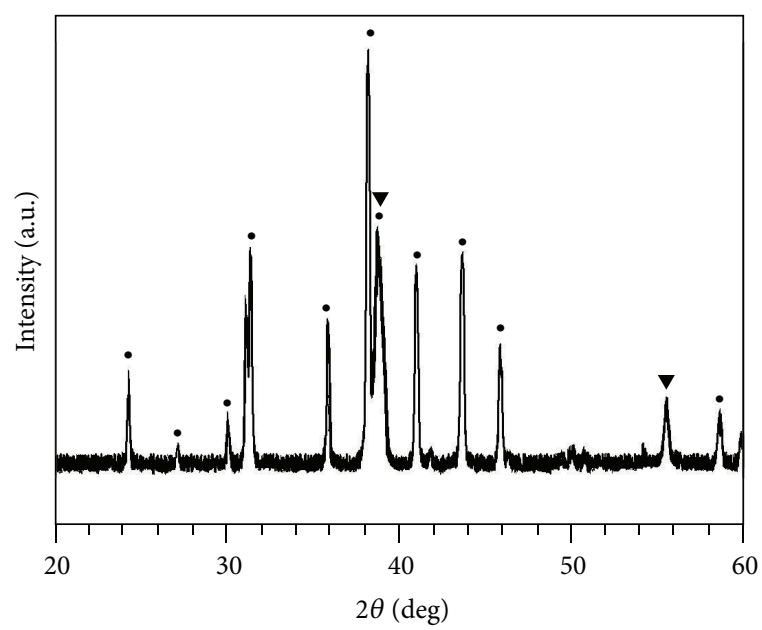

(c)

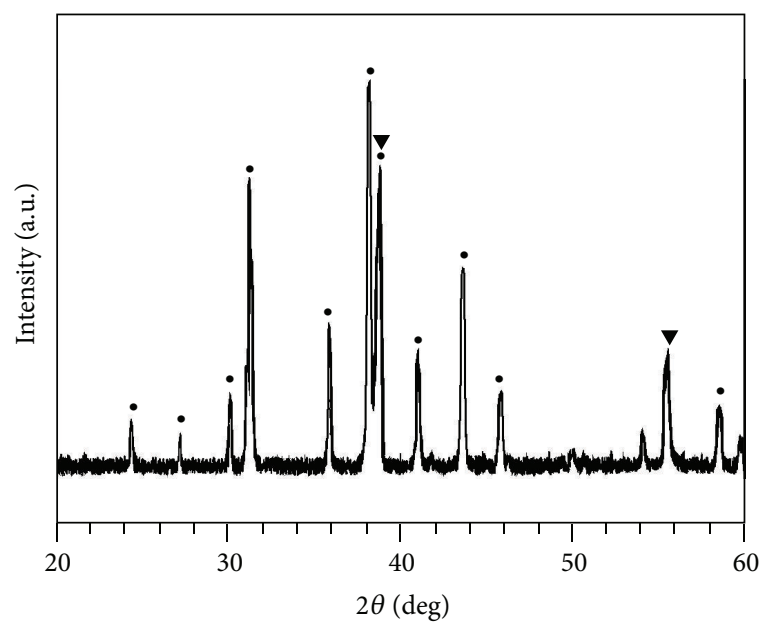

(b)

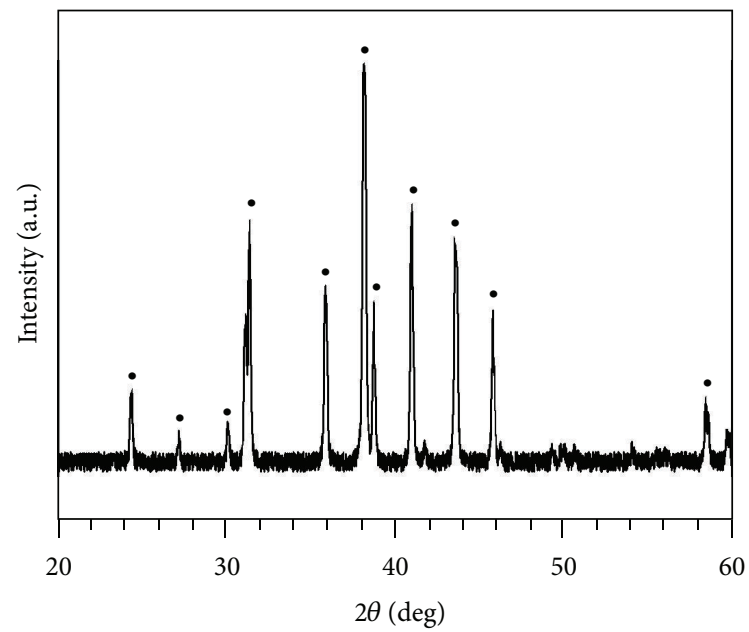

(d)

FIGURE 4: XRD patterns of four samples with different Nb/Si ratio: (a) Nb-10Si; (b) Nb-20Si; (c) Nb-30Si; (d) Nb-37.5Si.

alloy. It should be noted that only a very small part of $\mathrm{O}$ was still remained in both the white small particles and the grey areas. Although the $\mathrm{O}$ was not completely electrochemical reduced, it can be removed by other metallurgical methods in the consequent process. Typically, the mixed $\mathrm{Nb}_{2} \mathrm{O}_{5} / \mathrm{SiO}_{2}$ powder was almost completely electrodeoxidized in molten $\mathrm{CaCl}_{2}$ at $900^{\circ} \mathrm{C}$. For the processor powder mixture of Nb-20Si alloy, the product after electrolysis the SEM image was shown in Figure 3(b), which was similar to the image in Figure 3(a). The EDX results in the Table 1 also showed that the white particles were $\mathrm{Nb}$ and the grey areas were $\mathrm{NbSi}$ alloy (Nb20Si). The similar SEM image and EDX results were shown for the sample Nb-30Si alloy. Compare the three alloys (Nb$10 \mathrm{Si}, \mathrm{Nb}-20 \mathrm{Si}$, and $\mathrm{Nb}-30 \mathrm{Si}$ ), two conclusions were obtained. First, the grey areas in all the three images had $\mathrm{Nb}$ and $\mathrm{Si}$ concentrations close to 62.5 and 37.5 at \%, respectively, which was the atomic ratio in the $\mathrm{Nb}_{5} \mathrm{Si}_{3}$ alloy. Second, the white small particles were almost mainly composed of metallic $\mathrm{Nb}$.
Third, although $\mathrm{O}$ was remained in a little part in all the three samples, most of the $\mathrm{O}$ were still removed electrochemically. For the powder mixture of $\mathrm{Nb}-37.5 \mathrm{Si}$ alloy, the product after electrolysis, the SEM image, and EDX result were shown in Figure 3(d) and Table 1, respectively. Clearly, the product in the SEM image showed a homogenous phase with a $\mathrm{Nb} / \mathrm{Si}$ ratio of 62.2/37.0, which was also close to the atomic ratio of Nb5Si3.

To address the phase composition of the products in the four figures, the XRD patterns were obtained in Figure 4. All of the samples have a phase of $\mathrm{Nb}_{5} \mathrm{Si}_{3}$ (JCPDS: $30-0874$ ) as indicated with solid circle. Only the alloys of the Nb-10Si, Nb-20Si, and Nb-30Si had a phase of Nb (JCPDS: 35-0789) shown in Figures 4(a), 4(b), and 4(c). Based on the data of the XRD, SEM, and EDX, three critical conclusions can be drawn. First, all the samples were composed of two phases: $\mathrm{Nb}$ and $\mathrm{Nb}_{5} \mathrm{Si}_{3}$, which were the two phases in NbSi alloys. Second, in 
TABLE 1: EDX results of the four samples in Figure 3.

\begin{tabular}{lccc}
\hline Positions & $\mathrm{Nb}($ at $\%)$ & $\mathrm{Si} \mathrm{(at} \mathrm{\% )}$ & $\mathrm{O}($ at \%) \\
\hline a-white & 98.2 & 1.6 & 0.2 \\
a-grey & 62.1 & 37.6 & 0.3 \\
b-white & 99.1 & 0.8 & 0.1 \\
b-grey & 62.6 & 37.4 & - \\
c-white & 98.7 & 1.1 & 0.2 \\
c-grey & 62.7 & 37.0 & 0.3 \\
d & 62.2 & 37.5 & 0.4 \\
\hline
\end{tabular}

a-white, b-white, and c-white showed the concentrations of $\mathrm{Nb}, \mathrm{Si}$ and $\mathrm{O}$ in the positions of white small particles in Figures 3(a), 3(b), and 3(c), respectively. Similarly, a-grey, b-grey, and c-grey showed the concentrations of $\mathrm{Nb}, \mathrm{Si}$ and $\mathrm{O}$ in the positions of grey areas in Figures 3(a), 3(b), and 3(c), respectively. The concentrations of $\mathrm{Nb}, \mathrm{Si}$, and $\mathrm{O}$ in the sample $\mathrm{Nb}-37.5 \mathrm{Si}$ alloy in Figure 3(d) were shown in position d.

Figures 3(a), 3(b) and 3(c), the small white particles were $\mathrm{Nb}$ phase, and grey phase was $\mathrm{Nb}_{5} \mathrm{Si}_{3}$. Third, the $\mathrm{Nb}-37.5 \mathrm{Si}$ sample was completely composed of $\mathrm{Nb}_{5} \mathrm{Si}_{3}$ phase after electrolysis.

\section{Conclusion}

We used four mixed powders of different $\mathrm{Nb}$-Si compositions (Nb-10Si, Nb-20Si, Nb-30Si, and Nb-37.5Si) for NbSi alloys preparation. NbSi alloys can be prepared by direct electrochemical reduction method in molten $\mathrm{CaCl}_{2}$ at $900^{\circ} \mathrm{C}$, which is an easy and one-plot procedure. After electrolysis, $\mathrm{Nb}$ phase showed white scattered particles in the grey $\mathrm{Nb}_{5} \mathrm{Si}_{3}$ phase under SEM. XRD, and EDX results have proved that the $\mathrm{NbSi}$ alloys were successfully obtained, which had paved a creative way for production of alloys with direct electrochemical reduction method.

\section{Acknowledgments}

The authors are grateful for the Science and Technology Ministry of China for the financial support to the national high technology project.

\section{References}

[1] M. Singh and D. R. Behrendt, "Reactive melt infiltration of silicon-niobium alloys in microporous carbons," Journal of Materials Research, vol. 9, pp. 1701-1708, 1994.

[2] C. L. Ma, A. Kasama, R. Tanaka, and S. Hanada, "Development of Nb-Nb-silicide in-situ composites," Transactions of Metal Heat Treatment, vol. 21, p. 2, 2000.

[3] M. G. Mendiratta and D. M. Dimiduk, "Microstructures and mechanical behaviors of 2-phase niobium silicide-niobium alloys," in Proceedings of the Material Research Society Symposia Proceeding, vol. 133, MRS, Pittsburgh, Pa, USA, 1989.

[4] W. Y. Kim, H. Tanaka, A. Kasama, and S. Hanada, "Microstructure and room temperature fracture toughness of $\mathrm{Nbss} / \mathrm{Nb}_{5} \mathrm{Si}_{3}$ in situ composites," Intermetallics, vol. 9, no. 9, pp. 827-834, 2001.

[5] X. Y. Yan and D. J. Fray, "Production of niobium powder by direct electrochemical reduction of solid $\mathrm{Nb}_{2} \mathrm{O}_{5}$ in a eutectic
$\mathrm{CaCl}_{2}-\mathrm{NaCl}$ melt," Metallurgical and Materials Transactions B, vol. 33, pp. 685-693, 2002.

[6] T. Nohira, K. Yasuda, and Y. Ito, "Pinpoint and bulk electrochemical reduction of insulating silicon dioxide to silicon," Nature Materials, vol. 2, no. 6, pp. 397-401, 2003.

[7] G. Z. Chen, D. J. Fray, and T. W. Farthing, "Direct electrochemical reduction of titanium dioxide to titanium in molten calcium chloride," Nature, vol. 407, no. 6802, pp. 361-364, 2000.

[8] F. K. Meng and H. M. Lu, "Study on a new electrolysis technology of preparing high $\mathrm{Nb}$ bearing TiAl alloy from metal oxides," in EPD Congress Proceedings, pp. 711-717, 2009.

[9] G. Z. Chen, E. Gordo, and D. J. Fray, "Direct electrolytic preparation of chromium powder," Metallurgical and Materials Transactions B, vol. 35, pp. 223-233, 2004.

[10] F. Meng and H. Lu, "Direct electrochemical preparation of NbSi alloys from mixed oxide preform precursors," Advanced Engineering Materials, vol. 11, no. 3, pp. 198-201, 2009.

[11] A. J. M. Wood, R. C. Copcutt, G. Z. Chen, and D. J. Fray, "Electrochemical fabrication of nickel manganese gallium alloy powder," Advanced Engineering Materials, vol. 5, no. 9, pp. 650653, 2003.

[12] K. Dring, R. Bhagat, M. Jackson, R. Dashwood, and D. Inman, "Direct electrochemical production of Ti-10W alloys from mixed oxide preform precursors," Journal of Alloys and Compounds, vol. 419, no. 1-2, pp. 103-109, 2006. 

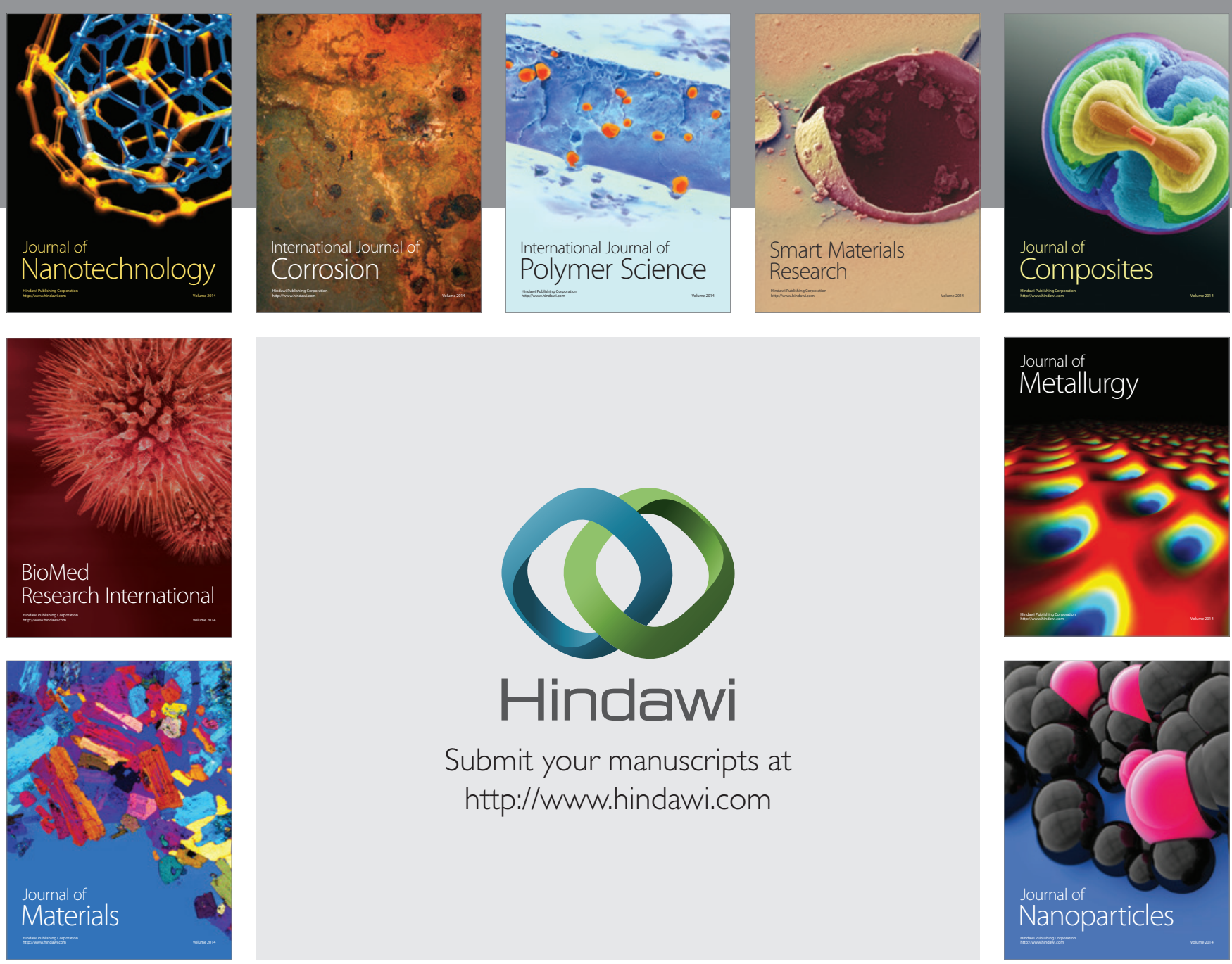

Submit your manuscripts at http://www.hindawi.com
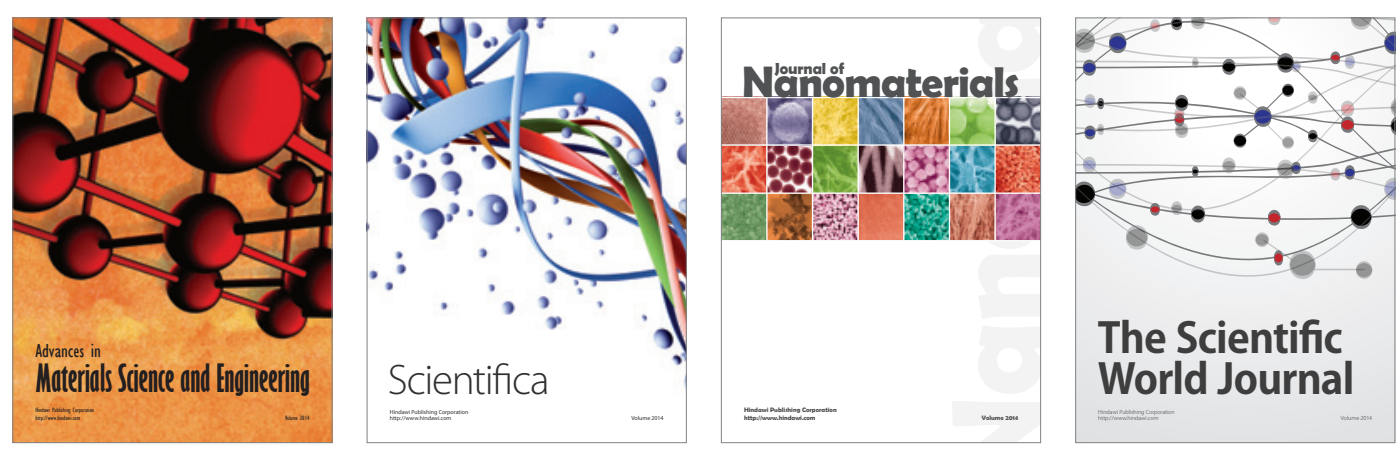

\section{The Scientific World Journal}
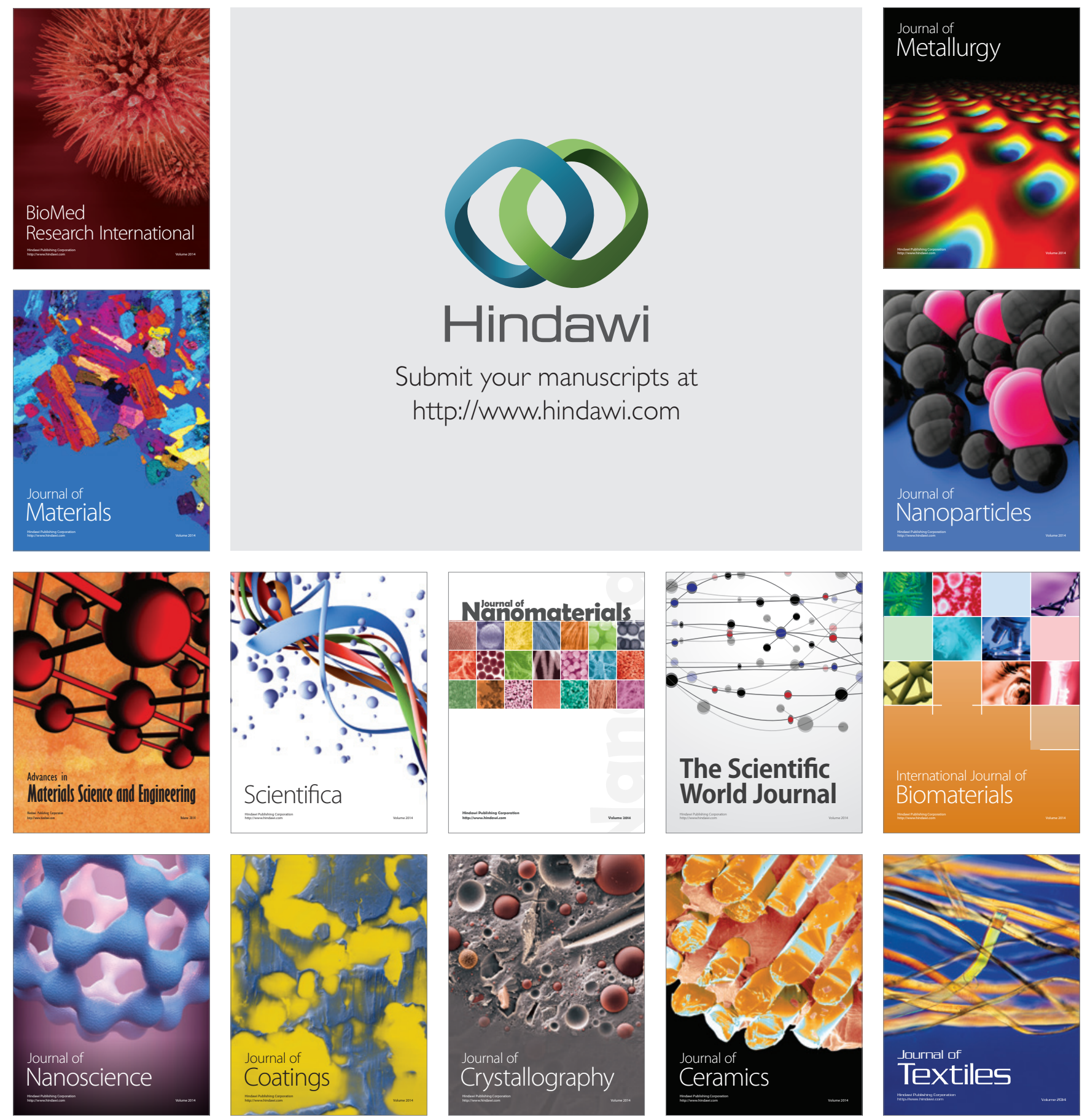